International Research Journal of Public and Environmental Health Vol.9 (1),pp. 16-23, February 2022

Available online at https://www.journalissues.org/IRJPEH/

https://doi.org/10.15739/irjpeh.22.003

Copyright (C) 2022 Author(s) retain the copyright of this article

ISSN 2360-8803

\title{
Herbal medicine practice in Ghana: A cross-sectional study to understand the factors influencing patient utilization of herbal medicine services
}

Anthony Nketia 1*, Emmanuel Nakua ${ }^{2}$, Andrews William

Tetteh ${ }^{3}$, Kwesi Prah Thomford4, Kwame 0. Boadu', Ama Kyeraa Thomford 6 and

Richmond $\mathrm{Amo}^{7}$

${ }^{1}$ Department of Health Promotion, Education and Disability Studies, School of Public Health, Kwame Nkrumah University of Science and Technology, Kumasi, Ghana.

2Department of Epidemiology and

Biostatistics, School of Public Health,

Kwame Nkrumah University of Science and Technology, Kumasi, Ghana.

${ }^{3}$ Herbal Medicine Unit, Kumasi South Hospital, Kumasi, Ghana

4Department of Pharmacognosy and Herbal Medicine, School of Pharmacy and

Pharmaceutical Sciences, University of Cape Coast, Cape Coast, Ghana.

${ }^{5}$ Department of Maternal and Child

Health, Kumasi South Hospital, Kumasi, Ghana.

6Department of Biomedical Sciences, Faculty of Allied Health Sciences, University of Cape Coast, Ghana. ${ }^{7}$ Obstetrics and Gynecology Department, Kwame Nkrumah University of Science and Technology Hospital, Kumasi

*Corresponding Author

Email: nketiaanthony@gmail.com
The practice of herbal medicine is the most prevalent form of traditional medicine or complementary and alternative medicine utilized in many countries across the globe. This study assesses the factors influencing the use and preference for herbal medicines compared to orthodox medicines among clients visiting some selected herbal units in the Kumasi Metropolis operating under the Ghana Health Service. A cross-sectional study was conducted. Primary data was collected from 413 participants using semi-structured questionnaires. Convenience sampling technique were used to select the participants. Results indicated that $80.90 \%$ of the respondents interviewed preferred herbal medicines to orthodox medicines. Factors influencing this preference were occupation, nature/severity of condition and cost of certified herbal drugs dispensed at the herbal unit. Also, respondents sought the services of the herbal unit for conditions which orthodox treatment outcomes are poor. The overall cost of certified herbal products prescribed at these units were considered as affordable by participants. Herbal medicine is preferred compared to orthodox medicine by patients utilizing the services of the herbal unit at government hospitals within Kumasi Metropolis.

Keywords: Cross-sectional studies, herbal medicine practice, integration, traditional medicine.

\section{INTRODUCTION}

The practice of traditional medicine (TM) has seen great advancement with guidelines being issued regarding collaboration with biomedicine (Richer, 2003). There are several forms of $\mathrm{TM}$ therapies available and herbal medicine is the most utilized and popular form (Maclennan et al., 2006; Diouf et al., 2013).

With the practice of herbal medicine gaining more global recognition, a number of people have turned to its use 
either as a complement or as an alternative to allopathic medicine (Lucas, 2010; Adjei, 2013). Evidence suggests that approximately $80.0 \%$ of Africans rely on herbal medicine for their primary healthcare (PHC) needs. Myriad of reasons underpin this patronage and utilization of herbal medicines. These reasons alter from culture to culture and race to race. Common reasons indicated for the use of herbal medicines include availability and accessibility, effectiveness, safety, affordability as well as its cultural compatibility (Aziato and Antwi, 2016).

The availability of herbal medicines in many developing countries such as Ghana highly outweighs the availability of allopathic medicines. Therefore, most people when ill or confronted with health problem resort to herbal therapies. Besides the widespread availability of herbal medicines, easy accessibility to practitioners also explains the widespread use of herbal medicines in Africa and some developing countries (WHO, 2013). Allopathic practitioners are mainly located in the urban areas with a limited number in the rural settings. Therefore, as opined by Abdullahi (2011) for millions of people in rural settings, native healers including herbal medicine practitioners continue to serve as their provider of health.

A study by Nyeko et al. (2016), indicated that perception and belief in the efficacy of herbal medicines also influences its use even among pregnant women. Shaikh and Hatcher (2005) reported that herbal therapies are often touted as curing both chronic and acute ailments. This impression can be erroneous as the belief that all herbal medicines are safe. Socio-cultural compatibility also underpins the reason regarding the enormous utilization of herbal medicines (Darko, 2009). The use of similar dialect by practitioners during their interaction has been extrapolated as enhancing the efficacy of treatments and strengthens the bond between practitioner and patients.

In Ghana, herbal medicine services have been integrated into the formal healthcare delivery system giving the practice a different form. This new outlook makes it imperative to understand the factors influencing the utilization and preference for herbal medicines among clients utilizing herbal unit at government hospital. We report on the most significant of these factors in this study.

\section{METHODS}

\section{Study Design and Setting}

A cross-sectional design was employed in the collection of quantitative data for the study. The study was conducted in 3 government hospitals in the Kumasi metropolis. These hospitals were selected because they have herbal unit manned by Medical Herbalist, who are a group of certified healthcare professionals with training from the Kwame Nkrumah University of Science and Technology (KNUST). The surveyed hospitals included the Tafo government hospital, Suntreso government hospital and the Kumasi South government hospital.

\section{Study Area}

The Kumasi Metropolis is one of the thirty (30) districts in Ashanti Region of Ghana with a population of 1,730,249. It shares boundaries with Kwabre East and Afigya Kwabre Districts to the north, Bosomtwe District to the south, Asokore Mampong and Ejisu-Juaben Municipality to the east, and Atwima Kwanwoma and Atwima Nwabiagya Districts to the west. (Issahaku and Amuquandoh, 2013)Figure 1.

Although, almost all the ethnic groups in Ghana can be found in this Metropolis, the largest group are the Asantes $(80.7 \%)$ which is a sub-group of the larger Akan ethnic group. The Kumasi metropolis has 136 health facilities of which 115 are owned by private individuals. The biggest health facility within the metropolis is the Komfo Anokye Teaching Hospital (KATH) which is a modern teaching hospital widely used by residents and others from Ghana and neighboring countries (GSS, 2014). Doctor to patient and nurse to patient ratio in the metropolis are 1:41,606 and 1:7866 respectively (Agyei-Baffour et al., 2017).

\section{Target population}

The target population were clients who sought medical service from the herbal unit within these selected government hospitals in the Kumasi Metropolis. Individuals who were 18 years and above were engaged in the study. This approach ensured that the respondents were matured, could make informed decisions by themselves, and also contributed meaningfully and effectively to the study.

\section{Sampling technique}

The Cochran formula was used to determine the sample size (Cochran, 1977). A $95 \%$ confidence level and 5\% margin of error were used. A study conducted by Agyei-Baffour et al. (2017) ascertained that out of the total clients (patients) who visit government hospitals having herbal medicine unit, $42.2 \%$ access the service of the herbal unit. Hence, by the Cochran's formula, the required sample size was calculated to be.

$$
\mathrm{N}=\frac{(1.96)^{2} *(0.422)(1-0.422)}{(0.05)^{2}}=374.8 \approx 375
$$

Making provision for $10 \%$ non-response, $10 \%$ of $375=37.5$ $\approx 38$

Therefore, the total number of participants recruited for the study $=375+38=413$

The catchments size for Tafo government hospital, Suntreso government hospital and Kumasi-South government hospital are 236619, 357886 and 448097 respectively (Agyei-Baffour et al., 2017). A sample size of 94, 142 and 177 was obtained for Tafo government hospital, Suntreso government hospital and Kumasi-South government hospital respectively. 


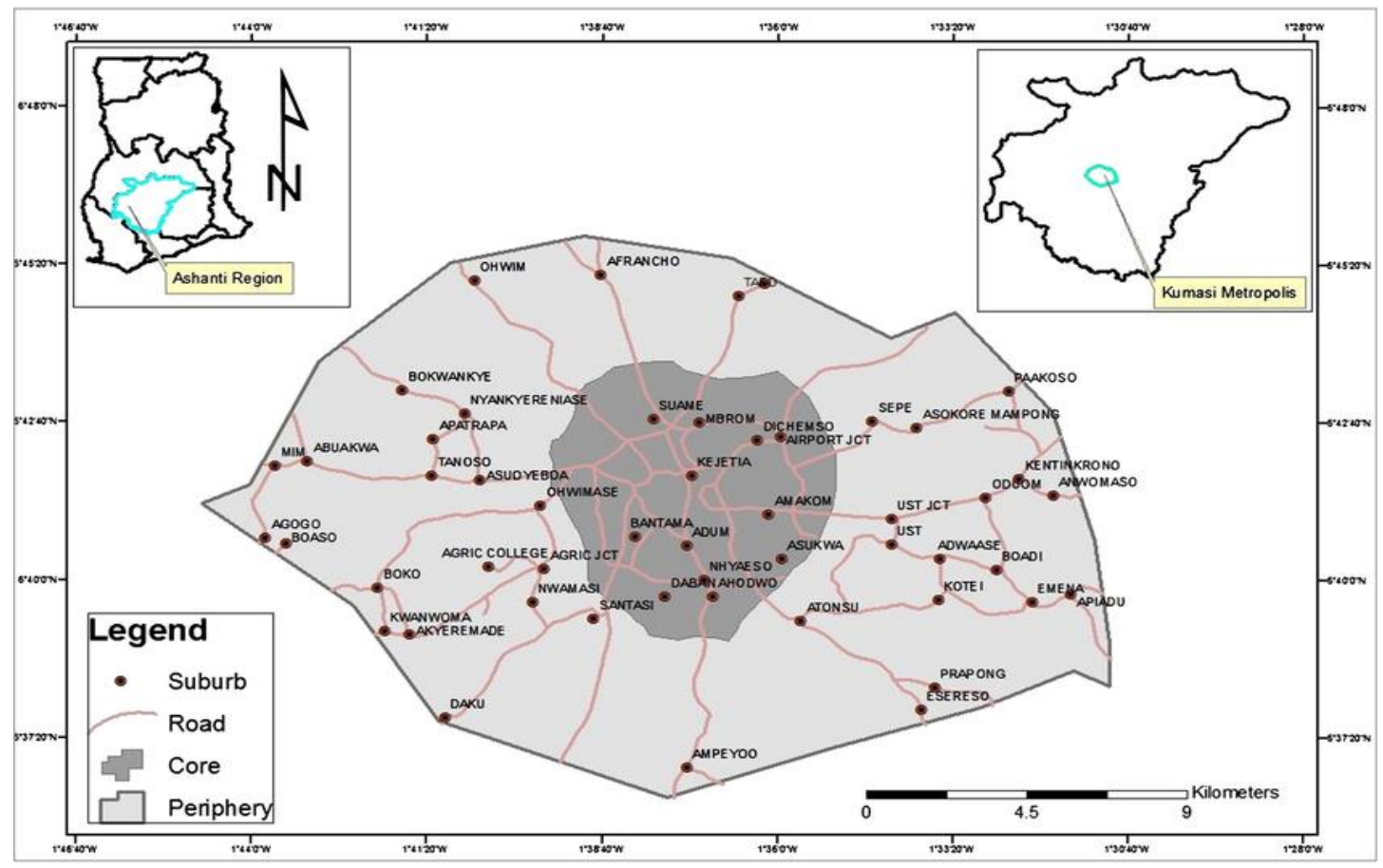

Credit: Issahaku \& Amuquandoh, 2013

Figure 1: An outline of the geographical region: Kumasi Metropolitan area, used for this survey.

\section{Data Collection and Analysis}

A semi-structured questionnaire was the tool used to obtain the primary data. Informed consent and permission to participate in the study were sought from each participant. After the data collection, the questionnaires were reviewed, responses were coded and analyzed using STATA software version 14 . The analysis employed cross tabulations, chi-square, and logistic regression. Chi-square analysis was conducted to ascertain the association between preference for herbal medicine to orthodox medicine and other selected variables. Multivariate logistic regression was used to establish factors which influence preference for herbal medicine to orthodox medicine. Tests of analysis were explored at a significance level of 0.05 .

\section{RESULTS}

\section{Socio-demographic characteristics of study participants}

A total of 413 respondents were engaged in the study. The age range of 18-35 years accounted for $50.9 \%$ of the respondents. The median age was 35 years and the mean age (SD) was 38.73 (15.23). Female respondents accounted for $223(54.0 \%)$ of participants. Approximately 152 $(37.0 \%)$ of the respondents had secondary education as their highest educational background. Majority 349 (84.5\%) were Christians. Also, 231 (55.9 \%) of the respondents were married. The major occupation of the respondents was trading. A detailed description of the socio-demographic characteristics of the respondents is presented in Table 1 below.

\section{Respondents' use and preference for herbal medicine}

From Table 2, respondents engaged in the study all admitted to prior usage of orthodox medicine medical services. In assessing the frequency of use of the herbal units, 205 (50.3\%) of the participants responded that they were utilizing the herbal unit for the second time. On the whole, 182 (44.6\%) of the respondents mostly utilized the services rendered at the herbal unit for conditions which orthodox treatment fails. Interestingly, $330(80.9 \%)$ of participants using the herbal unit responded during interview that they preferred herbal medicines to orthodox medicines. Reasons which informed respondents' preference were hinged on attitude of herbal practitioners 192 (58.2\%), easily accessibility and availability of herbal medicine services 90 (27.3\%), safety of herbal medicines $117(35.5 \%)$ as well as efficacy of herbal treatment 254 (77.0\%).

\section{Factors influencing patient preference for herbal medicine to orthodox medicine}

Respondents' occupation, conditions for which respondents seek the services rendered at the herbal unit and the cost of certified herbal drugs dispensed at the herbal unit were 
Table 1. Socio-Demographic Characteristics of Respondents

\begin{tabular}{|c|c|c|}
\hline Variable & $\begin{array}{c}\text { Frequency } \\
(\mathrm{N}=413)\end{array}$ & $\begin{array}{c}\text { Percent } \\
\text { (\%) }\end{array}$ \\
\hline \multicolumn{3}{|l|}{ Age } \\
\hline $18-35$ years & 210 & 50.85 \\
\hline $36-59$ years & 147 & 35.59 \\
\hline$\geq 60$ years & 56 & 13.56 \\
\hline \multicolumn{3}{|l|}{ Median $=35$ years } \\
\hline \multicolumn{3}{|l|}{ Range $=18-82$ years } \\
\hline \multicolumn{3}{|l|}{ Mean \pm S.D $=38.73 \pm 15.23$} \\
\hline \multicolumn{3}{|l|}{ Sex } \\
\hline Male & 190 & 46.0 \\
\hline Female & 223 & 54.0 \\
\hline \multicolumn{3}{|l|}{ Educational Level } \\
\hline No formal education & 40 & 9.69 \\
\hline Basic education (Primary and JHS) & 90 & 21.79 \\
\hline Secondary education (Middle school/SHS) & 152 & 36.80 \\
\hline Tertiary & 131 & 31.72 \\
\hline \multicolumn{3}{|l|}{ Religion } \\
\hline Christianity & 349 & 84.50 \\
\hline Islam & 55 & 13.32 \\
\hline Traditional & 8 & 1.94 \\
\hline None & 1 & 0.24 \\
\hline \multicolumn{3}{|l|}{ Marital Status } \\
\hline Single & 146 & 35.35 \\
\hline Married & 231 & 55.93 \\
\hline Divorced & 18 & 4.36 \\
\hline Widowed & 18 & 4.36 \\
\hline \multicolumn{3}{|l|}{ Occupation $(n=402)$} \\
\hline Farmer & 37 & 9.20 \\
\hline Trader & 123 & 30.60 \\
\hline Public servant & 110 & 27.36 \\
\hline Other business & 97 & 24.13 \\
\hline Unemployed & 35 & 8.71 \\
\hline
\end{tabular}

associated with preference for herbal medicine to orthodox medicine (Table 3). In terms of occupation, public servants had the highest odds of preference for HM to OM (OR: 6.59; CI: 2.37-18.36; p-value: 0.005). Also, respondents who sought the services rendered at the herbal unit for conditions which orthodox treatment had failed increased the odds of preference for HM to OM (OR: 6.78; CI: 2.40-19.17; p-value: 0.001). Moreover, respondents who considered the overall cost of certified herbal prescribed at the herbal unit as inexpensive had increased odds of preference for HM to OM (OR: 8.94; CI: 2.01-39.87; p-value: 0.004) (Table 4).

\section{DISCUSSION}

According to Boateng et al. (2016), the biomedical healthcare system in Ghana is seen as structurally superior whiles herbal medicine can be viewed as functionally strong. It was therefore representative that all the participants had used biomedical healthcare at a point in addressing their health needs. Together, these two healthcare systems serve the health needs of all Ghanaians (Boateng et al., 2016). The study revealed that majority of patients who seek health care from the herbal unit available at government hospitals do so for conditions which orthodox treatment fail. This supports the findings of a published work which argued that allopathic cannot cure all diseases or health conditions (Ohemu et al., 2017). It also gives strength to the argument that for easily diagnosed ailments which have well-established cures, such as malaria, patients prefer to go to orthodox medicine practitioners, but for chronic health problems they seek the services of TMP's and other modern CAM practitioners such as Medical Herbalists (Tabuti, 2004).

A high preference for herbal medicine by users of the facility was reported. This position may reflect patient satisfaction with the services provided by the herbal unit at government hospitals. A study by Agyei-Baffour et al. (2017), also found a high level of satisfaction with services provided to users at the health facilities. Patients were probed further to ascertain reasons underpinning their preference for herbal medicine to orthodox medicine. The characteristic reason of efficacy was predominant. With regards to the efficacy, herbal medicines have already been tagged for its significant success in healing acute as well as chronic diseases (Boadu and Asase, 2017).

Other reasons dictating respondents' preference for 
Table 2. Respondents' use and preference for herbal medicine

\begin{tabular}{|c|c|c|}
\hline Variable & $\begin{array}{l}\text { Frequency } \\
(n=408)\end{array}$ & $\begin{array}{l}\text { Percent } \\
(\%)\end{array}$ \\
\hline \multicolumn{3}{|l|}{ Ever used orthodox medicine $(n=408)$} \\
\hline Yes & 408 & 100.00 \\
\hline \multicolumn{3}{|c|}{ Frequency of use of the herbal unit within the hospital } \\
\hline First time/once & 61 & 14.95 \\
\hline Twice & 205 & 50.25 \\
\hline Thrice & 78 & 19.12 \\
\hline More than thrice & 64 & 15.69 \\
\hline \multicolumn{3}{|c|}{$\begin{array}{l}\text { For which condition do you seek the service of a Medical } \\
\text { herbalist? }\end{array}$} \\
\hline For all ailments & 126 & 30.9 \\
\hline For chronic conditions & 75 & 18.4 \\
\hline For conditions which orthodox treatment fails & 182 & 44.6 \\
\hline For non-life threatening health conditions & 25 & 6.1 \\
\hline \multicolumn{3}{|l|}{ Do you prefer HM to OM? } \\
\hline Yes & 330 & 80.88 \\
\hline No & 78 & 19.12 \\
\hline \multicolumn{3}{|l|}{ Reasons for preference for HM to OM? * } \\
\hline Attitude of herbal practitioners & 192 & 58.18 \\
\hline Easy accessibility and availability & 90 & 27.27 \\
\hline The safety of herbal medicines & 117 & 35.45 \\
\hline The efficacy of herbal medicines & 254 & 76.97 \\
\hline \multicolumn{3}{|c|}{$\begin{array}{l}\text { How would you rate the overall cost of certified herbal drugs } \\
\text { dispensed to you? }(n=408)\end{array}$} \\
\hline Very expensive & 210 & 51.47 \\
\hline Moderate & 142 & 34.80 \\
\hline Not expensive & 56 & 13.73 \\
\hline
\end{tabular}

* Multiple response

Table 3. Factors associated with preference for HM to OM

\begin{tabular}{|c|c|c|c|c|}
\hline \multirow[t]{2}{*}{ Variables } & \multicolumn{2}{|c|}{$\begin{array}{l}\text { Preference for herbal } \\
\text { medicine to orthodox } \\
\text { medicine }\end{array}$} & \multirow[t]{2}{*}{$x^{2}$} & \multirow[t]{2}{*}{$P$ - value } \\
\hline & $\begin{array}{c}\text { Yes } \\
\text { n(\%) }\end{array}$ & $\begin{array}{c}\text { No } \\
\text { n(\%) }\end{array}$ & & \\
\hline \multicolumn{5}{|l|}{ Age } \\
\hline $18-35$ & $169(41.4)$ & $40(9.8)$ & & \\
\hline $36-59$ & $118(28.9)$ & $25(6.1)$ & 0.8551 & 0.652 \\
\hline$\geq 60$ & $43(10.5)$ & $13(3.2)$ & & \\
\hline \multicolumn{5}{|l|}{ Sex } \\
\hline Male & $149(36.5)$ & $36(8.8)$ & 0.0256 & 0.873 \\
\hline Female & $181(44.4)$ & $42(10.3)$ & & \\
\hline \multicolumn{5}{|l|}{ Educational level } \\
\hline No formal education & $31(7.6)$ & $9(2.2)$ & & \\
\hline Basic education & $73(17.9)$ & $17(4.2)$ & 0.5605 & 0.905 \\
\hline Secondary education & $122(29.9)$ & $30(7.4)$ & & \\
\hline Tertiary education & $104(25.5)$ & $22(5.4)$ & & \\
\hline \multicolumn{5}{|l|}{ Religion } \\
\hline Christianity & $273(66.9)$ & $71(17.4)$ & & \\
\hline Islam & $48(11.8)$ & $7(1.7)$ & 4.0951 & 0.251 \\
\hline Traditional & $8(2.0)$ & 0 & & \\
\hline None & $1(0.3)$ & 0 & & \\
\hline \multicolumn{5}{|l|}{ Marital status } \\
\hline Single & $113(27.7)$ & $32(7.8)$ & & \\
\hline Married & $190(46.6)$ & $37(9.1)$ & 4.4050 & 0.221 \\
\hline Divorced & $12(2.9)$ & $6(1.5)$ & & \\
\hline Widowed & $15(3.7)$ & $3(0.7)$ & & \\
\hline
\end{tabular}


Table 3 Cont.

\begin{tabular}{|c|c|c|c|c|}
\hline \multicolumn{5}{|l|}{ Occupation } \\
\hline Farmer & $31(7.8)$ & $6(1.5)$ & \multirow{6}{*}{34.4155} & \multirow{6}{*}{ 0.001* } \\
\hline & $99(24.9)$ & $24(6.1)$ & & \\
\hline Trader & $94(23.7)$ & $11(2.8)$ & & \\
\hline Public servant & $82(20.7)$ & $15(3.9)$ & & \\
\hline Other business & $16(4.0)$ & $19(4.8)$ & & \\
\hline \multirow{2}{*}{\multicolumn{5}{|c|}{$\begin{array}{l}\text { Unemployed } \\
\text { Conditions for which respondents seek the services } \\
\text { rendered at herbal unit }\end{array}$}} \\
\hline & & & & \\
\hline All ailments & $80(19.6)$ & $46(11.3)$ & \multirow{4}{*}{54.9951} & \multirow{4}{*}{ 0.001* } \\
\hline Chronic conditions & $67(16.4)$ & $8(2.0)$ & & \\
\hline Condition which orthodox treatment fails & $169(41.4)$ & $13(3.2)$ & & \\
\hline Non-life threatening health conditions & $14(3.4)$ & $11(2.7)$ & & \\
\hline \multicolumn{5}{|c|}{$\begin{array}{l}\text { Cost of certified herbal drugs dispensed at the } \\
\text { herbal unit }\end{array}$} \\
\hline Very expensive & $147(36.0)$ & 64(15.7) & \multirow{3}{*}{36.1343} & \multirow{3}{*}{0.001} \\
\hline Moderate & $130(31.9)$ & $12(2.9)$ & & \\
\hline Not expensive & $53(13.0)$ & $2(0.5)$ & & \\
\hline
\end{tabular}

${ }^{*}$ Chi-Square statistic is significant at the 0.05 level

Table 4. Multivariable logistic regression of factors influencing preference for $\mathrm{HM}$ to $\mathrm{OM}$

\begin{tabular}{|c|c|c|c|c|c|}
\hline \multirow[t]{2}{*}{ Covariates } & \multicolumn{2}{|c|}{$\begin{array}{l}\text { Preference for herbal } \\
\text { medicine to orthodox } \\
\text { medicine }\end{array}$} & \multirow[t]{2}{*}{ OR } & \multirow[t]{2}{*}[95\%\mathrm{CI}]{} & \multirow[t]{2}{*}{$P$ - value } \\
\hline & $\begin{array}{l}\text { Yes } \\
\text { no(\%) }\end{array}$ & $\begin{array}{c}\text { No } \\
\text { no(\%) }\end{array}$ & & & \\
\hline \multicolumn{6}{|l|}{ Occupation } \\
\hline Unemployed & $16(4.0)$ & $19(4.8)$ & 1.00 & & \\
\hline Trader & $99(24.9)$ & $24(6.1)$ & 3.81 & [1.51 - 9.64] & 0.012 \\
\hline Farmer & $94(23.7)$ & $11(2.8)$ & 4.86 & [1.42 - 16.67] & 0.001 \\
\hline Public servant & $82(20.7)$ & $15(3.9)$ & 6.59 & {$[2.37-18.36]$} & 0.005 \\
\hline Other business & $31(7.8)$ & $6(1.5)$ & 5.1 & [1.93 - 13.73] & 0.001 \\
\hline \multicolumn{6}{|c|}{$\begin{array}{l}\text { Conditions for which } \\
\text { respondents seek the services } \\
\text { rendered at herbal unit } \\
\text { Non-life threatening health }\end{array}$} \\
\hline $\begin{array}{l}\text { Non-life threatening health } \\
\text { conditions }\end{array}$ & $14(3.4)$ & $11(2.7)$ & 1.00 & & \\
\hline $\begin{array}{l}\text { Conditions which orthodox } \\
\text { treatment fails } \\
\text { Chronic conditions }\end{array}$ & $169(41.4)$ & $13(3.2)$ & 6.78 & [2.40 - 19.17] & 0.001 \\
\hline All ailments & $\begin{array}{l}67(16.4) \\
80(19.6)\end{array}$ & $\begin{array}{c}8(2.0) \\
46(11.3)\end{array}$ & $\begin{array}{l}3.57 \\
1.21\end{array}$ & $\begin{array}{c}{[1.13-11.22]} \\
{[0.46-3.18]}\end{array}$ & $\begin{array}{l}0.030 \\
0.693\end{array}$ \\
\hline \multicolumn{6}{|c|}{$\begin{array}{l}\text { Cost of certified herbal drugs } \\
\text { dispensed at the herbal unit } \\
\text { Very expensive }\end{array}$} \\
\hline Moderate & $147(36.0)$ & $64(15.7)$ & 1.00 & & \\
\hline Not expensive & $130(31.9)$ & $12(2.9)$ & 3.92 & [1.91 - 8.08] & 0.001 \\
\hline & $53(13.0)$ & $2(0.5)$ & 8.94 & {$[2.01-39.87]$} & 0.004 \\
\hline
\end{tabular}

Outcome variable: Preference for HM to OM; HM Herbal Medicine; OM: Orthodox Medicine

herbal medicine were also found to include attitude of herbal practitioners, safety of herbal medicines as well as easily accessibility and availability of herbal medicine services. The reasons stated have been reported in several earlier studies as accounting for the patronage and utilization of herbal medicines and its services in general
(Bamidele et al., 2009; Darko, 2009; Aziato and Antwi, 2016; Agyei-Baffour et al., 2017).

The study also established that occupation, nature of condition as well as cost of certified herbal drugs dispensed at the herbal unit are significant determinants of a person's preference for herbal medicine. Hence, it is implied that 
occupational status of a person, nature/severity of health condition (ailment) and the cost involved in obtaining certified herbal drugs serve as indispensable factors influencing patronage and utilization of $\mathrm{HM}$ at the various government hospitals. The occupational and cost factors could be linked to the ability to pay for the certified herbal drugs. The nature/severity as a factor could also be related to the effectiveness of herbal drugs in the management and treatment of certain kinds of diseases.

\section{Strength and Limitations of the study}

The study provides significant qualitative data on factors influencing patients' preference for herbal medicine services to that of orthodox medicines in government hospitals in Ghana. Interviewing participants from all three government hospitals with herbal units within the Kumasi Metropolis enhances the generalizability of the study findings. The study might suffer some form of bias owing to the certain aspect of the methodology. For instance, the questionnaires were drafted in English and unfortunately some respondents could not read. This might have caused information or measurement bias. Moreover, convenience sampling was used to select clients for the study which have potential selection bias and reduces the utility of the findings. However, measures such as interpreting questionnaire from English to local dialect (Twi) for respondents was adopted to ensure that such bias is reduced to minimal.

\section{Conclusion}

There is high preference for HM to that of OM among patients who utilize the services of herbal unit at government hospitals within Kumasi Metropolis. This shows the functionality of services of integrated herbal medicine process as in health care delivery in Ghana.

\section{Acknowledgement}

The authors are exceedingly grateful to all the respondents and also to the Medical Herbalists at Tafo government hospital, Suntreso government hospital and Kumasi South government hospital for giving audience and providing all the assistance needed during the study.

\section{Funding}

No funding agency supported this study.

\section{Ethical approval}

All study protocol was reviewed and approved by the Institutional review board of KNUST- The Committee on Human Research and Publication Ethics (CHPRE).

\section{Competing interest}

The authors declare that they have no competing interests.

\section{REFERENCES}

Abdullahi AA (2011). Trends and challenges of traditional medicine in Africa. African J. Traditional, Complementary and Alternative Medicine, 8: 115-123.

Agyei-Baffour P, Kudolo A, Quansah DY, Boateng D (2017). Integrating herbal medicine into mainstream healthcare in Ghana: clients' acceptability, perceptions and disclosure of use. BMC Complementary and Alternative Medicine,17 (513):1-9.

Adjei B (2013). Utilization of Traditional Herbal Medicine and Its Role in Health. Unpublished thesis (MPhil), Kwame Nkrumah University of Science and Technology.

Aziato L, Antwi HO (2016). Facilitators and barriers of herbal medicine use in Accra, Ghana: an inductive exploratory study. BMC Complementary and Alternative Medicine, 16(142): 1-9.

Bamidele JO, Adebimpe WO, Oladele EA (2009). Knowledge, attitude and use of alternative medical therapy amongst urban residents of Osun state, southwestern Nigeria. African J. Traditional, Complementary and Alternative Medicines, 6 (3): 281-288.

Boadu AA, Asase A (2017). Documentation of herbal medicines used for the treatment and Management of Human Diseases by some communities in southern Ghana. Evid Based Complement Alternat Med, 17:1-12.

Boateng AM, Danso-Appiah A, Turkson B, Tersbøl PB (2016). Integrating biomedical and herbal medicine in Ghana - experiences from the Kumasi South Hospital: a qualitative study. BMC Complementary and Alternative Medicine, 16(189): 1-8.

Cochran WG (1977). Sampling techniques (3rd ed.). New York: John Wiley \& Sons.

Darko IN, (2009). Ghanaian Indigenous Health Practices: The Use of Herbs. Unpublished thesis (MA). Ontario Institute for Studies in Education, University of Toronto.

Diouf M, Boetsch G, Ka K, Tal-Dia A, Bonfil JJ (2013). Socio-cultural aspects of oral health among the Fulani in Ferlo (Senegal): a qualitative study. Acta Odontol Scand, 71(5):1290-1295

Ghana Statistical Service. (2014). 2010 population and housing census: District Analytical Report, Kumasi Metropolitan. Available at: www.statsghana.gov.gh. Accessed on $12^{\text {th }}$ July, 2020.

Harun-Or-Rashid, Yoshitoku Y, Aminur R, Salmun N, Junichi S (2011). Perceptions of the Muslim religious leaders and their attitudes on herbal medicine in Bangladesh: a cross-sectional study. BMC Research Notes, 4(366):1-9.

Issahaku A, Amuquandoh FE (2013). Dimensions of hotel location in the Kumasi Metropolis, Ghana. Tourism Management Perspectives, 8:1-8

Lucas GN, (2010). Herbal Medicine and Children. Sri Lanka 
J. Child Health, 39:76-78.

Maclennan AH, Myers SP, Taylor AW (2006). The continuing use of complementary and alternative medicine in South Australia: costs and beliefs in 2004 . MJA, 184(1):27-31.

Nasri H, Shirzad H (2013). Toxicity and safety of medicinal plants. Journal of Herbal Medicine Pharmacology, 2(2):21-22.

Nyeko R, Tumwesigye NM, Halage AA (2016). Prevalence and factors associated with use of herbal medicines during pregnancy among women attending postnatal clinics in Gulu district, Northern Uganda. BMC Pregnancy and Childbirth,16(296):1-12.

Ohemu TL, Sariem CN, Dafam DG, Ohemu BO, Okwori VA, Olotu PN, Jerome CO,(2017). Knowledge, attitude and practice of traditional medicine among people of Jos North Local Government area of Plateau State, Nigeria. Int. J. Pharmacognosy and Phytochemical Res., 9(10): 1353-1358.
Shaikh BT, Hatcher J, (2005). Complementary and Alternative Medicine in Pakistan: Prospects and Limitations. Evidence-Based Complementary and Alternative Medicine, 2(2):139-142.

Tabuti JR (2004). The traditional medicine practitioners (TMPs) and attitudes of the rural community of Bulamogi County (Uganda) towards traditional medicine: preliminary findings. African J. Ecol., 42:40-41.

World Health Organization. (2013). Traditional Medicine: Executive Board, 134 Session. Provisional agenda item 9.1, EB134/24, 13 December 2013. 